\title{
Cruzando fronteiras de gênero: a docência feminina em campos profissionais "masculinos"*
}

\author{
Neiva Furlin**
}

\begin{abstract}
Resumo
A tarefa da docência superior, em algumas áreas acadêmicas, ao longo de muitos anos, foi considerada uma atribuição exclusiva do sujeito masculino. Este trabalho evidencia a participação feminina na docência no ensino superior de teologia, as dinâmicas de poder que produzem desigualdades de gênero, bem como as estratégias políticas que as mulheres constroem para constituírem-se sujeitos femininos de saber teológico, em um espaço historicamente estruturado como não inteligível para elas. Embora reduzida, a presença feminina nesse campo de saber torna-se significativa por desestabilizar uma ordem social que parecia ser sagrada $e$ intocável.
\end{abstract}

Palavras-chave: Fronteiras de gênero, Docência feminina, Teologia católica, Diferença sexual.

* Recebido para publicação em 06 de outubro de 2015, aceito em 11 de agosto de 2016.

** Doutora em Sociologia pelo Programa de Pós-Graduação da Universidade Federal do Paraná.nfurlin@yahoo.com.br. 
Crossing Gender Limits: Female Teaching in "Masculine" Professional Fields

\begin{abstract}
For many years, the task of teaching in certain academic fields was considered an exclusive attribution of masculine subjects. This essay puts in evidence the female participation in academic teaching in superior theology courses, the power dynamics which cause gender inequality, and the political strategies constructed by women to constitute themselves as female subjects of theological knowledge, in a space historically structured as not intelligible to them. Albeit small in number, the female presence in this field of knowledge is becoming significant by destabilizing a social order that seemed to be sacred and untouchable.
\end{abstract}

Key Words: Gender frontiers, Female teaching, Catholic theology, Sexual difference. 


\section{Contextualização e perspectiva teórico-metodológica}

A docência feminina no ensino superior tem sido uma conquista recente em diferentes áreas acadêmicas $e$ vem se afirmando em meio a desafios, sobretudo nos campos de saberes que se estruturaram, ao longo de muitos séculos, como espaços exclusivamente masculinos. Aqui poderíamos citar as áreas da engenharia, da física, da matemática, da filosofia, da teologia, entre outras. Neste trabalho, nos interessa discutir sobre as dinâmicas de gênero e de poder que se inscrevem no campo do saber da teologia católica, a partir da inserção de mulheres na docência.

Convém mencionar que as instituições católicas de ensino em teologia foram criadas em vista da formação para o ministério ordenado de homens. Historicamente, esse espaço foi marcado por formas de organização androcêntricas que garantiram a supremacia do sujeito masculino nas instâncias hierárquicas do espaço eclesial e sua exclusividade na produção do discurso acadêmico teológico. As representações de gênero desse discurso instituído no plano do sagrado e do simbólico acabaram legitimando o campo do saber teológico como um lugar não inteligível para as mulheres. No Brasil, elas só tiveram acesso ao curso superior de teologia a partir da década de 1970, quando as mulheres foram cruzando as fronteiras demarcadas pelo gênero em diferentes áreas acadêmicas. Esse fenômeno ocorreu impulsionado pelas transformações socioculturais e pelas mobilizações feministas, as quais, indubitavelmente, também influenciaram o ambiente religioso e eclesial. Assim, a partir dos anos 1980, as mulheres não estavam mais somente acessando aos cursos de teologia, mas também se inserindo no ensino e na produção acadêmica de seu campo.

É importante mencionar que recentemente a graduação em teologia foi reconhecida pelo Ministério da Educação (MEC), por meio do Parecer do Conselho Nacional de Educação - CNE/CES 
$\mathrm{n}^{\circ} 241 / 99$, de $15 / 03 / 99^{1}$, o que trouxe maior visibilidade para essa área disciplinar no conjunto das ciências humanas, tornando-se um espaço de saber aberto para quem deseja essa formação, fazendo dela um projeto profissional, para além da histórica formação para o serviço presbiteral.

O presente trabalho procura evidenciar a participação da docência feminina nos cursos de graduação em teologia, algumas dinâmicas de poder que produzem desigualdades de gênero, $e$ as estratégias políticas que as mulheres constroem para afirmarem-se como sujeitos femininos de saber teológico em um espaço historicamente estruturado como não inteligível para elas.

Este artigo é um recorte da tese de doutorado, intitulada Relações de gênero, subjetividades e docência feminina: um estudo a partir do universo do ensino superior em teologia, recentemente concluída. A coleta das informações e o levantamento dos dados empíricos exigiram uma combinação de técnicas que incluiu pesquisa bibliográfica, consulta a páginas eletrônicas das instituições católicas de ensino teológico, aplicação de questionário, participação em congressos de teólogos/as, análise de programas de ensino e a realização de entrevistas aprofundadas.

$\mathrm{O}$ instrumento para a coleta dos dados quantitativos foi enviado a todas as instituições católicas de ensino superior em teologia do Brasil. No período da pesquisa ${ }^{2}$, havia 71 instituições, as quais se distribuíam nas categorias: universidades católicas, centros universitários, faculdades e institutos diocesanos ${ }^{3}$. Com o retorno de 40 questionários, obteve-se a participação de 56,3\% delas. Isso possibilitou estabelecer um quadro de evidência aproximado e válido acerca da participação feminina e masculina no universo do ensino da teologia. Permitiu, ainda, situar, de forma contextualizada, em nível nacional, algumas dinâmicas e

\footnotetext{
1 Até então, os cursos eram considerados "cursos livres" em teologia.

2 Ano de 2008.

${ }^{3}$ Esta última categoria refere-se às instituições em que o curso superior de teologia ainda não era legalizado junto ao Ministério da Educação.
} 
aspectos dessas instituições, segundo os indicativos selecionados para o questionário. ${ }^{4}$

Entre as técnicas utilizadas foi dado destaque às entrevistas em profundidade, como um meio de dar voz às interlocutoras da pesquisa e escutar as narrativas sobre suas trajetórias de inserção no campo acadêmico teológico, suas ações, relacionamento com seus pares, processos de resistência e experiências no exercício das atividades acadêmicas nesse universo. De modo que foram entrevistadas 14 mulheres docentes inseridas em três instituições católicas que possuíam o curso graduação em teologia - duas universidades e uma faculdade, localizadas nos estados do Rio de Janeiro, Paraná e Rio Grande do Sul. Convém lembrar que entre os critérios para a seleção das docentes se estabeleceu que elas tivessem formação em teologia católica e produção acadêmica na perspectiva de gênero, ou que tivessem tido algum contato com a abordagem da teologia feminista no período da formação acadêmica. $^{5}$

Para além de uma análise fria de números, este artigo resulta de uma abordagem qualitativa de compreensão hermenêutica, segundo os pressupostos produzidos por Maria Cecília Minayo (2003), que privilegiam a relação intersubjetiva entre pesquisadora e interlocutoras. Assim sendo, este estudo deu voz às mulheres docentes, cujas narrativas sobre suas experiências permitiram evidenciar suas ações, sua relação com estrutura e com os demais sujeitos que interagiam no espaço acadêmico, bem como as suas lutas, resistências e estratégias políticas produzidas no processo de tornarem-se sujeitos femininos de um saber que lhes foi privado durante muito tempo. As narrativas dessas

4 Os indicativos selecionados foram: tipo de instituição; tempo de funcionamento do curso de teologia; situação atual no MEC; número de discentes e docentes, por sexo; faixa etária dos/as docentes; nível de formação e local de formação dos/as docentes; critérios de contratação.

${ }^{5}$ Isso porque acredita-se que a pessoa que teve contato com essa teologia ou produz nessa perspectiva de conhecimento consegue perceber e problematizar melhor as dinâmicas de gênero que circulam no cotidiano das práticas sociais, de modo que se tornou um critério importante, diante da proposta da pesquisa. 
docentes revelaram, ainda, que elas assumem uma postura reflexiva sobre os limites e as dinâmicas de poder da ordem masculina profissional, em uma trajetória de tornarem-se sujeitos de saber que foi traçada ativamente nas relações com o mundo social, e não por meio de uma recepção passiva diante das convenções sociais e institucionais de gênero. De acordo com a socióloga inglesa Margaret S. Archer (2009), é nisso que reside o sujeito ativo da sociologia. ${ }^{6}$ Por meio de suas próprias ações, que envolvem a experiência, essas mulheres foram produzindo uma nova subjetividade que se opõe ao modelo do sistema simbólico masculino, o que nos leva a concordar com Maria Cecília Minayo (2003), de que elas também se objetivam em sua própria ação e, disso decorre a sua subjetivação.

Desse modo, priorizamos abordar a memória das experiências vividas e narradas pelas docentes sobre as suas relações com os discentes e com seus pares de profissão, o que permitiu compreender as dinâmicas de poder $e$ as estratégias políticas que elas construíram para cruzar fronteiras de gênero $e$ legitimarem-se sujeitos femininos de saber teológico. Também buscamos evidenciar os índices da participação feminina $e$ masculina na docência no ensino superior de teologia, na tentativa de estabelecer um quadro de evidências sobre a configuração deste universo de saber. Trata-se de um campo profissional no qual o discurso teológico tradicional legitimou, por excelência, a supremacia do sujeito masculino.

A análise e a compreensão do material de campo foram realizadas segundo as concepções teóricas dos estudos feministas e de gênero da perspectiva pós-estruturalista, nas definições que envolvem as relações de poder e seus efeitos, e os processos de resistência e de subjetivação ética. Destacamos, aqui, os principais conceitos que atravessam a compreensão hermenêutica deste

\footnotetext{
${ }^{6}$ Segundo essa autora, dar "voz" aos sujeitos nos dá melhores explicações sobre o que eles realmente fazem e permite aos agentes avaliarem reflexivamente seus contextos sociais e objetivos em termos de suas preocupações pessoais e decisão sobre o curso de sua ação social.
} 
estudo: a) Gênero desde a perspectiva de Joan Scott (1990) e Tereza de Lauretis (1994); b) Poder como uma relação produtiva, conforme as noções de Michel Foucault (1999) e Judith Butler $(2007)^{7}$; c) Subjetividade ética na compreensão de Foucault (2004, 2007), pensada como a constituição de si por meio de atos de liberdade, resistência e de reflexividade diante das convenções normativas que limitam as condições do sujeito; d) Diferença sexual, segundo a compreensão de Braidotti (2004), como um processo de positivação da diferença ou da produção de um feminino alternativo ao modelo do sistema simbólico masculino. Para isso, Braidotti focaliza a resistência na prática política feminista e na localização do corpo encarnado, para produzir efeitos de contramemória. É partindo da perspectiva da prática localizada que ela propõe uma versão não essencializada da Diferença Sexual ${ }^{8}$, em que o eu encarnado se define com a intersecção de muitos campos de forças sociais, tais como raça, idade, cultura. Se o sistema simbólico masculino colonizava o imaginário das mulheres, para Braidotti, "o projeto do feminismo deve tanto resistir como abrir espaços alternativos para as mulheres redefinirem coletivamente suas experiências singulares como o "outro de si mesmas" (Braidotti, 1999:16); e) Agência

${ }^{7} \mathrm{Na}$ releitura que Judith Butler (2009a) faz de Foucault, ela reafirma que o sujeito não é produzido totalmente pela norma ou por discursos, e nem tampouco consegue ignorar a norma que se instaura em sua reflexividade. Segundo essa autora, há sempre uma luta com as condições da própria vida que poderia não ter sido uma escolha e, nessa luta, existe algum ato de agência ou de liberdade que se produz em um contexto facilitador e limitante, ao mesmo tempo, no sentido de sempre haver algum tipo de coerção. Isto é, para autora, nós construímos uma agência ética de nós mesmos no contexto das relações, a partir daquilo que incorporamos em nossa formação, que é parte do nosso status de seres constituídos nas relações de dependência, e pelo esforço reflexivo de dar conta de si, em contextos de relações sociais, situação que pode ser evidenciada na trajetória das docentes entrevistadas, em seu processo de tornarem-se sujeitos femininos de saber teológico.

8 A crítica de Rita Felski (1999) é que apesar de a teoria da Diferença Sexual contemporânea buscar esvaziar a feminilidade de qualquer conteúdo essencialista, ela continua assumindo a prioridade da divisão entre masculino $e$ feminino. 
compreendida conforme Butler (2003, 2009a, 2009b) e Braidotti (2004). Para Butler, o poder da agência é fundamentalmente resistência. Surge quando se dá uma descontinuidade entre o poder que constitui o sujeito e o poder que o próprio sujeito assume. Em palavras de Butler (2010:9): "a agência excede ao poder que lhe faz possível". É esse excesso que oferece a possibilidade de ressignificação que surge do desejo do sujeito, $e$ o desejo "tem por objetivo a dissolução do sujeito", nesse caso, o sujeito conformado com as convenções sociais. Em Braidotti (2004), a agência também se conecta com o processo de resistência ao sistema simbólico masculino que produziu subjetividades femininas pejorativas e estáveis, de maneira que o potencial subversivo da agência se encontra na relativa não pertença a esse sistema, o que lhes permite negociar ou produzir formas alternativas de sujeito.

Esses pressupostos teóricos foram fundamentais para compreender os processos de resistência ao sistema simbólico de gênero, da ordem social masculina, que construiu o feminino como inferior e despossuído de razão, bem como as estratégias políticas que as docentes criam para cruzar as fronteiras de gênero $e$ se produzirem sujeitos femininos de saber, no cotidiano da profissão da docência, em um lugar, ainda, marcadamente masculino.

\section{Cruzando fronteiras de gênero: a participação feminina no ensino superior em teologia}

O curso superior de teologia historicamente se caracterizou como um "não lugar para as mulheres", tendo sido marcado por formas de organização androcêntricas, tanto na sua constituição como na produção do saber. Aqui, vale retomar o que já dissemos, que é a partir da década de 1970 que as mulheres começam a aparecer na docência do ensino superior em teologia, como ocorreu em outras áreas acadêmicas. De acordo com Margareth Rago (1998), ao ingressarem nas universidades, a partir 
dos anos 1970, elas começam a reivindicar o seu espaço na história, de modo que

a atuação feminina foi ganhando visibilidade, tanto pela simples presença das mulheres nos corredores e nas salas de aula, como pela produção acadêmica que vinha à tona. O mundo acadêmico foi ganhando novos contornos $e$ novas cores (Rago, 1998:91).

Bruschini e Lombardi (2002) mostram, por meio de dados quantitativos, que nas últimas décadas houve um aumento significativo da participação da docência feminina na educação superior.

O número de docentes na educação superior aumentou mais $102,2 \%$ nos últimos 10 anos, enquanto o número de participação masculina na docência aumentou 67,9\%. Essa proporção se estende também para os cursos de pósgraduação, indicando que as mulheres estão conseguindo ampliar sua inserção nesse campo do mercado de trabalho com mais facilidade do que em outros, porque estão se preparando mais (Bruschini; Lombardi, 2002:171).

No entanto, segundo seus estudos, os homens ainda formam a maior parte do corpo docente no ensino superior. Permanecem certos estereótipos de que algumas disciplinas como linguística, letras, artes e ciências humanas são para as mulheres, assim como as engenharias $e$ as ciências agrárias são para os homens. Isso mostra que as desigualdades de gênero ainda se manifestam de diversas maneiras no âmbito do sistema de ensino.

O Censo do INEP/MEC-2005 ${ }^{9}$ sobre o ensino superior no Brasil apresenta dados quantitativos da participação da docência masculina e feminina em todos os cursos, das diferentes grandes

9 Mantivemos os dados do Censo do INEP/MEC-2005 encontrados no site http://sinaes.inep.gov.br/sinaes/ em 2008 por não encontrar nos últimos Censos da Educação Superior dados que considerem a distribuição dos/as docentes por áreas detalhadas de atuação, segundo o sexo. 
áreas do saber acadêmico. A área de humanidades e artes é em que se evidencia a menor diferença entre docentes do sexo feminino e masculino, quando comparada às outras grandes áreas, mesmo que nela os homens ainda tenham predominância. Em cada curso que compõe essa grande área de conhecimento encontramos diferenças específicas. Citamos aqui dois cursos nos quais aparece uma diferença acentuada na participação da docência masculina e feminina. Por exemplo, na filosofia encontramos 1.145 docentes do sexo masculino, para 661 do sexo feminino. Já no curso de letras, há 1.619 mulheres para 720 homens docentes. ${ }^{10}$ Poder-se-ia perguntar o que isso significaria em termos de uma perspectiva analítica de gênero? Na verdade, esses números mostram concretamente a existência de uma divisão sexual do trabalho docente. Isso porque a área das letras ainda aparece como o lugar das mulheres, e a filosofia, considerada historicamente como uma área do pensamento racional, continua, majoritariamente, masculina. Os dados quantitativos evidenciam que a equidade de gênero, na participação da docência no ensino superior, em diferentes áreas de saber acadêmico, continua sendo um desafio a ser superado.

$\mathrm{O}$ curso superior de teologia, entre os que integram a grande área das humanidades, é um dos que apresenta índices mais elevados de desigualdade entre a docência masculina $e$ feminina. ${ }^{11}$ Nesse sentido, a Tabela $1^{12}$ mostra dados da participação docente no campo do saber teológico, considerando os níveis de formação acadêmica. Nota-se que, no total, há uma

\footnotetext{
${ }^{10}$ Dados das tabelas encontradas no site: http://sinaes.inep.gov.br/sinaes/. Acesso em: 10 out. 2008.

${ }^{11}$ Para evidenciar essa questão utilizamos aqui dados encontrado no site do INEP e dados de pesquisa de campo realizada em novembro de 2008, a partir do recorte das instituições de confissão católica.

${ }^{12}$ Os dados da Tabela 1 pertencem ao Censo sobre o Ensino superior de 2005, cujos dados foram coletados em 93 instituições (presbiterianas, luteranas, metodistas e católicas) que ofereciam o curso de graduação de teologia registrado no MEC/INEP até aquele ano. Dessas 93 instituições, aproximadamente a metade era de orientação católica.
} 
diferença de 47,4 pontos percentuais entre a docência masculina $e$ a feminina. No que se refere à qualificação dos/as docentes, verificamos que em todos os níveis os homens apresentam um percentual mais elevado. No doutorado, por exemplo, a diferença é de 63,6 pontos percentuais. Enquanto há um número maior de homens docentes com doutorado, a representação da docência feminina é mais expressiva na titulação de especialista e vai se reduzindo à medida que se comparam os percentuais masculinos $e$ femininos com titulação de mestre e doutor. Mas, se olharmos em termos de números absolutos, considerando somente o sexo feminino, verifica-se que a participação das mulheres docentes tem maior expressão na titulação de mestrado $e$ se equipara aos homens quando se compara em termos absolutos. Entretanto, comparando sob o ponto de vista do número total de docentes, no nível de qualificação do mestrado, os homens superam as mulheres em 48,2 pontos percentuais, e essa diferença aumenta significativamente no nível de doutorado, para 63,6 pontos percentuais. Em termos de porcentagem, enquanto os docentes masculinos têm maior representação no nível do doutorado, as mulheres aparecem mais no nível de especialização, o que revela que se contratam mais mulheres com um nível inferior de qualificação $e$ isso repercute também nos salários e no lugar que ocupam na hierarquia das disciplinas (Furlin, 2011a).

Tabela 1 - Docentes de teologia em instituições confessionais por sexo, segundo nível de titulação máxima

\begin{tabular}{l|c|c|c|c|c}
\hline Nível de titulação & Feminino & $\mathbf{\%}$ & Masculino & $\mathbf{\%}$ & Total \\
\hline Doutorado & 56 & 18,2 & 251 & 81,8 & 307 \\
Mestrado & 104 & 25,9 & 298 & $\mathbf{7 4 , 1}$ & 402 \\
Especialização & $\mathbf{7 2}$ & $\mathbf{4 3 , 7}$ & 93 & 56,3 & 165 \\
Graduação & 22 & 23,7 & $\mathbf{7 1}$ & $\mathbf{7 6 , 3}$ & 93 \\
\hline Total & $\underline{\mathbf{2 5 4}}$ & $\mathbf{2 6 , 3}$ & $\underline{\mathbf{7 1 3}}$ & $\mathbf{7 3 , 7}$ & $\mathbf{9 6 7}$ \\
\hline
\end{tabular}

Fonte: Censo INEP/MEC- 2005. Disponível em: http://sinaes.inep.gov.br/sinaes/. Consulta em: jul. 2008.

A assimetria em relação à participação da docência feminina e masculina na teologia em instituições de diferentes confissões 
religiosas, que se observa na Tabela 1 , se amplia quando olhamos especificamente para essa mesma atividade no interior das instituições católicas, que é o que nos interessa neste estudo, ou seja, a diferença da participação chega a ser de 71,2 pontos percentuais, como evidencia a tabela abaixo. Isso, em parte, pode ser explicado pelas práticas discursivas da instituição eclesial católica ter, historicamente, legitimado hierarquias sexistas de participação no espaço eclesial, sobretudo, por ter vinculado o curso de teologia ao universo masculino, em vista do ministério ordenado, o que amplia ainda mais as desigualdades na participação entre docentes do sexo masculino e feminino.

Tabela 2 - Docentes de teologia em instituições católicas por sexo, segundo o nível de titulação máxima.

\begin{tabular}{l|c|c|c|c|c}
\hline \multicolumn{1}{c|}{ Nível de titulação } & Feminino & $\mathbf{\%}$ & Masculino & $\mathbf{\%}$ & Total \\
\hline Doutorado & 35 & 13,3 & 228 & 86,7 & 263 \\
Mestrado & 62 & 16,2 & 321 & 83,8 & 383 \\
Especialização & 16 & 24,2 & 50 & 75,8 & 66 \\
Graduação & 8 & 10 & 72 & 90 & 80 \\
\hline Total & 121 & 15,3 & 671 & $\mathbf{8 4 , 7}$ & $\mathbf{7 9 2}$ \\
\hline
\end{tabular}

Fonte: Elaboração da própria, a partir da pesquisa de campo. Novembro de 2008 .

Em relação ao nível de qualificação dos/as docentes, os dados da Tabela 2 vêm reafirmar que, também no âmbito da teologia católica, os homens atingem os percentuais mais elevados de representação em todos os níveis de formação. Praticamente as diferenças se repetem, porém com maior intensidade. Por exemplo, no nível de doutorado a diferença de participação, em 2008, chegava a ser de 74,5 pontos percentuais, quando comparado ao total de professores que atuavam na teologia. Por outro lado, se compararmos os números em termos absolutos, das 121 mulheres que atuavam na teologia, $28,9 \%$ possuíam doutorado e 51,2\% chegaram ao mestrado. Dos 671 homens professores, $33,9 \%$ eram doutores e $44,8 \%$ eram mestres. Esse 
olhar permite considerar que as poucas mulheres que atuam na teologia quase alcançam os níveis de formação do universo masculino. Contudo, os números de participação total revelam que no campo teológico católico há altos níveis de assimetria entre a docência masculina e a feminina. Certamente, medir estatisticamente essa não equidade não remove a desigualdade de acesso profissional a esse universo de saber, mas fornece um olhar objetivo sobre as estruturas discriminatórias em relação ao sexo feminino. ${ }^{13}$

Há também que se considerar que as mulheres que se inseriram nas instituições de ensino teológico, mesmo que tenham alcançado o maior nível de qualificação, precisam estar sempre provando que são competentes e capazes de assumir certas funções, até então, consideradas "masculinas". ${ }^{14}$ Assim como no mundo acadêmico em geral, o campo do ensino e da produção do saber teológico carrega, ainda, as marcas da ordem sociocultural masculina. Todavia, mesmo que as mulheres sejam uma minoria, em termos quantitativos, em um espaço considerado, ao longo de muitos anos, exclusivamente, do sujeito masculino, a sua presença e a sua ação ganham importância simbólica por revelar que as mulheres estão superando barreiras e fronteiras de gênero, transgredindo uma carreira profissional considerada masculina. Por outro lado, estando nesse lugar, elas precisam, constantemente, produzir estratégias de resistência à ordem simbólica masculina para constituírem-se sujeitos femininos de saber teológico (Furlin, 2011a).

Nesse sentido, na seção que segue, procuramos evidenciar como se produziu a desigualdade e a inferioridade das mulheres, bem como as estratégias políticas que elas utilizam para desconstruir os significados de gênero contidos nas representações simbólicas da teologia tradicional e masculina, ressignificando saberes e subjetividades.

\footnotetext{
${ }^{13}$ Outros dados quantitativos sobre a participação da docência feminina no ensino superior de teologia católica podem ser encontrados em Furlin (2011a).

${ }^{14}$ Essa questão é recorrente nas narrativas das docentes.
} 


\section{A produção da desigualdade de gênero $e$ a ressignificação de saberes e subjetividades}

Segundo as narrativas das docentes, a experiência de estar inserida no campo do saber teológico como professora, cujo espaço historicamente e culturalmente se naturalizou como o lugar do sujeito masculino e celibatário, requer delas uma construção contínua de espaços e posições conquistadas. Essa construção atravessa as relações que se estabelecem com os alunos, colegas de trabalho e com as estruturas de ensino, porque sutilmente ainda se reproduzem dinâmicas de poder $e$ de gênero que legitimam a razão teológica como um atributo exclusivamente masculino. Nesse sentido, Joan Scott (1990) já havia argumentado que o gênero é parte constituinte das relações sociais, que tomam por base as diferenças percebidas entre os sexos e, também, uma primeira maneira de significar as relações de poder.

Nosso estudo constatou diferentes dinâmicas de poder, que não só legitimaram a ausência histórica das mulheres nesse campo de saber, como também produziram e ainda produzem processos desiguais em relação ao gênero. Entre essas dinâmicas, priorizamos aqui dar ênfase ao discurso da teologia tradicional sobre as mulheres, que produziu a diferença pejorativamente, apoiando-se no pensamento grego - especificamente nos dualismos da filosofia de Aristóteles e nas tradições do judaísmo, cujas ideias e representações influenciaram a filosofia e a teologia moral de Agostinho e de Tomás de Aquino. ${ }^{15}$ Trata-se de um discurso que foi materializando e naturalizando práticas sociais discriminatórias, que justificavam a exclusão das mulheres em espaços de liderança eclesial, conforme se lê em um dos fragmentos do pensamento de Tomás de Aquino.

A igualdade entre os dois sexos existe no plano da graça $e$ da salvação, mas não no plano da natureza, pois a virtude ativa que se encontra na semente do macho visa produzir

\footnotetext{
${ }^{15}$ Os saberes produzidos por esses autores continuam integrando os programas de ensino da teologia católica.
} 
algo que se assemelhe em perfeição ao sexo masculino. Se por acaso uma mulher for gerada, é em função da fraqueza dessa virtude ativa ou de alguma má disposição da matéria, ou até de alguma transmutação vinda do exterior. [...] $\mathrm{O}$ sexo feminino não pode significar superioridade em nada, porque o estado da mulher é sujeição. Ela não pode, portanto, receber o sacramento da ordem (Aquino, Suma Teológica vol.2, 1980:92, art. I).

Ao sustentar a ideia de que as mulheres estariam num estado de subordinação e inferioridade, se justificava a sua incapacidade para o serviço ordenado. Em outras palavras, essa subordinação aos homens e a sua inferioridade vista como "condição da natureza" era, para Tomás de Aquino, o verdadeiro motivo para negar às mulheres qualquer ofício eclesial, como analisa uma teóloga feminista, norte-americana:

O afastamento das mulheres da liderança eclesial e do saber teológico foi realizado por meio da domesticação da mulher, sob a autoridade masculina. [...] De mãos dadas com essa eliminação e com a repressão de elementos emancipatórios dentro da Igreja, apresentava-se a justificação teológica da supressão da liderança feminina $e$ da patriarcalização do ofício eclesial. A trajetória da tradição paulina, que exige a submissão da mulher, por motivos teológicos, é um reflexo dessa evolução patriarcal $e$ reacionária da Igreja cristã (Fiorenza, 1995:99).

Pode-se dizer que esse discurso funcionou como uma tecnologia de gênero, na expressão de Teresa de Lauretis $(1994)^{16}$, por produzir subjetividades femininas submissas, materializar relações desiguais e estruturas hierárquicas, com base em uma

\footnotetext{
${ }^{16}$ Para Lauretis (1994), o gênero é compreendido como o conjunto de efeitos que são produzidos nos corpos por diferentes tecnologias sociais de gênero. Entre essas tecnologias, ela cita o cinema, os discursos que incluem as teorias epistemológicas e as práticas institucionais, bem como as práticas cotidianas, marginais aos discursos hegemônicos, situadas nas microrrelações políticas.
} 
determinada leitura da diferença entre os corpos masculinos $e$ femininos. Isso, em parte, explica a presença reduzida das mulheres que encontramos nos espaços da docência superior, na contemporaneidade (Furlin, 2015).

Desse modo, sendo os homens os sujeitos históricos da produção do saber teológico, da mesma forma que em outras áreas do conhecimento, esse saber reproduziu valores e interesses da cultura patriarcal. Segundo Schienbinger (2001), a visão masculina estruturou o conhecimento, desvalorizando $e$ negligenciando a participação histórica das mulheres nos processos socioculturais, já que as dinâmicas de gênero estabeleceram prioridades científicas, estruturando silenciosamente teorias e práticas sociais. Tanto os discursos filosóficos e científicos da modernidade como o da teologia tradicional legitimaram a universalização e a institucionalização de estruturas sociais hierárquicas $e$ androcêntricas. Isso levou teólogas e teóricas feministas a criticarem os discursos produzidos do ponto de vista da subjetividade masculina, por sua insuficiente atenção específica para a vida e para as experiências das mulheres. Tomou-se consciência de que a reiteração das representações de gênero, dos discursos androcêntricos, produziu a exclusão do universo feminino de instâncias significativas de poder e invisibilizou a sua contribuição nos processos históricos e culturais. Ou seja, as mulheres foram consideradas sujeitos "subalternos", no sentido de Gayatri Spivak (1985), porque não puderam expressar a sua voz e não havia instituição que as escutasse. Assim, o seu ato de fala não pôde ser levado a cabo, por carecer de autoridade legítima.

Muitos estudos da crítica cultural feminista apontaram o caráter masculino do pensamento ocidental. Entre esses, o de Felski (1995), que versa sobre a história da literatura, o de Adelman (2009) que tem grande acento na teoria social e os de Harding (1996), Chassot (2009) e Graf (2010), que priorizam a ciência. Considera-se, assim, que a ciência moderna é masculina não só porque os sujeitos são, em sua maioria, homens, mas sobretudo porque as representações simbólicas, crenças e valores que aparecem inscritos nesses saberes se conformam com os 
interesses masculinos. E isso não é diferente quando se fala da teologia, das humanidades e das artes, já que essas representações foram reiteradas ao longo da história, exercendo poder performativo na produção e na naturalização da inferioridade intelectual das mulheres.

Na mesma direção, as teólogas feministas americanas, que compartilhavam da crítica feminista feita nas diversas áreas acadêmicas, como Elisabeth Schüssler Fiorenza (1995), Rosemary R. Ruether (1983), Mary Daly (1985), apontaram que as representações simbólicas de gênero inscritas no discurso teológico tradicional produziram valores e crenças que serviram para normatizar comportamentos, práticas sociais e eclesiais $e$, consequentemente, construíram um modelo de feminino compatível com os projetos $e$ as práticas do próprio imaginário masculino. Nesse sentido, a teologia masculina tradicional se constituiu uma prática discursiva, reiterativa e citacional que, evidentemente, teve força para hierarquizar práticas sociais, baseadas no sexo biológico, segundo um modelo normativo de gênero que, no caso das instituições católicas, tornaram o "homem heterossexual celibatário" sujeito universal, inteligível e normativo para esse lugar de saber e a "mulher" como a despossuída de razão e, portanto, inferior (Furlin, 2014c).

Desse modo, os enunciados teológicos, produzidos sob a ótica masculina e em contextos patriarcais, desde a antiguidade, foram construindo o feminino como o "Outro", ou o feminino como negativo e inferior, na relação com a supremacia do masculino como sujeito. Assim, o fato de algumas teólogas elaborarem uma leitura crítica do pensamento masculino, na teologia católica, mostra que, ainda que tardiamente, elas participaram da crítica que o feminismo da igualdade e da diferença, da década de 1970, fazia aos discursos masculinos e aos seus efeitos, em diferentes campos científicos. Isso porque foi a partir dos anos 60 , do século XX, que o feminismo começou a desnaturalizar a construção da "mulher" como o "outro", inferior e despossuído de racionalidade. Direcionou a sua crítica aos mitos, às imagens $e$ às representações sobre as mulheres, como 
uma construção da imaginação masculina, questionando a suposta neutralidade e objetividade do sujeito, nos processos de produção do saber.

No Brasil, essa crítica feita à teologia tradicional masculina, ocorreu a partir dos anos de 1980, quando um grupo de mulheres teólogas foi se constituindo em sujeitos reflexivos e tomou consciência do poder dos discursos simbólicos, na produção das subjetividades femininas. Desse modo, elas mostraram que as imagens $e$ as representações femininas inscritas na teologia tradicional eram uma criação do imaginário masculino, cuja produção buscava legitimar os interesses do universo masculino, naturalizando hierarquias de gênero $e$, consequentemente, a inferioridade das mulheres. Essas teólogas compartilhavam da mesma busca de outras mulheres feministas, inseridas em diferentes campos acadêmicos, porque pretendiam desnaturalizar discursos, desconstruir e ressignificar as representações simbólicas de gênero da teologia que elas nomearam androcêntrica. Essa expressão sintetiza todo um sistema de pensamento centrado nos valores e nas identidades masculinas, em que a "mulher" era considerada apenas o "outro", a irrepresentável, a inferior, em referência ao masculino. Ou no sentido usado por Llanos (2010), o androcentrismo é uma prática comum e generalizada, que vai além da linguagem discursiva e se encontra, também, nas práticas culturais e institucionais, como é o caso das instituições teológicas.

É importante mencionar que, no Brasil, a crítica mais expressiva ao pensamento teológico masculino foi feita por Ivone Gebara. Essa teóloga chamou a atenção para as representações simbólicas dos discursos teológicos masculinos, apontando que essa simbologia tinha um interesse político, justamente por ser usada para orientar valores e crenças que interferiam nas práticas sociais e eclesiais, exercendo poder sobre os sonhos, os comportamentos e as condutas. Isto é, trata-se de um discurso que exerce poder performativo, uma vez que produz determinados tipos de subjetividades femininas e masculinas.

A constatação dessas dinâmicas de poder fez com que teólogas feministas, no contexto da teologia brasileira, 
estrategicamente selecionassem alguns aspectos do amplo $e$ complexo discurso teológico para fazer uma releitura de textos, imagens e mitos bíblicos que evocavam representações simbólicas e conceitos normativos e que exerciam poder na produção do gênero, nesse caso, do feminino como inferior. Para desnaturalizar e ressignificar essas representações de gênero, elas assumiram o que chamaram de hermenêutica da suspeita e da imaginação ${ }^{17}$, tomando por base as experiências corporificadas das mulheres $e$ os instrumentais analíticos dos estudos feministas, o que permitia não só a ressignificação dos saberes, mas também uma produção ética de si, como aparece na voz de uma teóloga.

A mulher vai descobrindo uma nova maneira de fazer teologia, a partir da tomada de consciência da fecundidade libertadora de uma releitura bíblica, e da necessidade de descobrir a sua própria identidade, "desconhecendo o lugar" que o homem lhe outorgou e que foi por ela introjetado (Tepedino, 1985:376).

Assim, elas criaram situações de tensões com o que estava colocado, isto é, produziram novos significados que desafiavam a ordem simbólica e normativa do campo de saber, assumindo, nos interstícios desse lugar, uma posição de sujeito ético que faz dos limites a sua possibilidade, como têm evidenciado as teorias foucaultiana e butleriana: um sujeito capaz de produzir saber e de, ao mesmo tempo, ressignificar a própria subjetividade, ou seja,

\footnotetext{
${ }^{17}$ Segundo Oliveira (2006:03), "a hermenêutica da suspeita é um exercício que confronta interpretações conservadoras; desconstrói paradigmas androcêntricos e patriarcais dos textos bíblicos e os reconstrói com referenciais libertadores; pergunta pela ideologia que envolve o texto, os protótipos e estereótipos; pergunta pelo tipo de sociedade, pelas relações de poder entre homens $e$ mulheres, das mulheres entre si, dos homens entre si. A hermenêutica da imaginação intui a possibilidade de uma imaginação criativa como uma regra metodológica fundamental no processo interpretativo. A imaginação criativa viabiliza a capacidade de pensar um mundo diferente e melhor".
} 
um sujeito feminino também dotado de razão teológica. ${ }^{18}$ Pode-se entender esse processo de ressignificação dos discursos e da subjetividade feminina como estratégias de resistência, no qual ocorre o poder da agência, e que, segundo Butler (2010), surge quando ocorre uma descontinuidade entre o poder que constitui o sujeito e o poder que o próprio sujeito assume. Trata-se de uma agência que excede ao poder que lhe tornou possível, oferecendo a possibilidade de ressignificação. Tal ressignificação surge do desejo do sujeito, nesse caso de mulheres teólogas e docentes que buscam, pela prática e pela produção de saberes, dissolver uma subjetividade feminina subalterna inferior, conformada com as convenções culturais produzidas pelo discurso teológico tradicional.

Esse processo de agenciamento de si ocorre constantemente no cotidiano da profissão, como um vir a ser, uma vez que elas estão sempre se confrontando com dinâmicas de poder que, sutilmente, operam no sentido de controlar as fronteiras demarcadas para cada gênero. Em nossa pesquisa, essa luta aparece desde os processos de inserção no campo do saber teológico, das relações que se estabelecem no período da formação e quando já estão assumindo a prática docente, nos espaços de poder que podem ou não se abrir para as mulheres. Ilustramos isso com a narrativa de Rute, que aborda algo de uma experiência coletiva, no período em que ela era estudante de teologia.

Quando nós entramos aqui, os seminaristas, na época, tiveram uma reação muito forte. Diziam que o nível iria abaixar, porque essas mulheres vêm para cá estudar, então o nível vai abaixar. Os professores perceberam que nós estávamos aqui para estudar, não estávamos aqui para fazer brincadeira, para passar o tempo. Isso acirrou mais ainda a raiva de alguns seminaristas. Então, o primeiro ano foi bastante difícil, mas depois eles chegaram à conclusão

${ }^{18}$ Outros dados sobre a trajetória da teologia feminista no Brasil, consultar Furlin (2011b). 
de que o nível não abaixou. Muito pelo contrário, porque a gente já tinha outros cursos, sabia línguas e lia tudo. Então a gente conseguiu superar, mas no princípio foi duro. $\mathrm{O}$ primeiro ano foi mesmo porque a gente tinha muita vontade e se sentia chamada realmente. Era uma vocação mesmo, a gente buscar aprofundar para trabalhar melhor, mas foi difícil no início (Rute, 67 anos).

Nota-se que o confronto com a presença de mulheres no universo da teologia reativava um imaginário social em torno de um modelo de feminino, produzido pelos discursos teológicos tradicionais, fundado em concepções dualistas, como já relatamos neste artigo. Um imaginário que considerava a racionalidade teológica um atributo a priori masculino e o fato de ser mulher, por si só, já era um indicador de inferioridade intelectual. Por outro lado, o acesso a esse saber, por parte das mulheres, poderia ser percebido como uma ameaça à ordem eclesial histórica que legitimava a supremacia de poder que esses seminaristas pretendiam na carreira do ministério ordenado, de modo que, inicialmente, eles desqualificavam as experiências das mulheres, vindas de outros campos de saberes e de outras dinâmicas da vida. Esse discurso de desqualificação e de negação da capacidade feminina é uma forma de violência simbólica, porque, sutilmente, impõe fronteiras de gênero para o acesso das mulheres ao saber teológico, legitimando a hegemonia de poder e uma suposta defesa da racionalidade teológica como virtude masculina.

Esse exemplo e tantos outros, narrados pelas docentes, evidenciam que a todo tempo elas precisam construir estratégicas políticas para provar sua capacidade intelectual e sua eficiência profissional, no intuito de que sua ação interativa, com esse lugar de poder e de saber, enfraqueça os limites $e$ as fronteiras estabelecidas pelos poderes normativos $e$ as coloquem dentro de um contínuo processo de devir, como abordaremos no ponto que segue. 


\section{Sujeitos femininos de saber teológico: um processo de resistência e de "devir" 19}

Os resultados do nosso estudo apontam que o tornar-se sujeitos femininos de saber é um processo contínuo de resistência e de construção do próprio devir. E uma das estratégias para o devir tem sido a valorização positiva da diferença, como possibilidade política de ressignificação simbólica do feminino, que fora construído como pejorativo. Para isso, as docentes apelam às experiências corporificadas ou às ações localizadas que podem produzir o efeito de contramemória ao feminino moldado pela ordem simbólica masculina.

Nessa perspectiva, notamos a frequente valorização, por parte das docentes, de sua capacidade intelectual e das experiências que consideram singulares no universo feminino, que vêm das diferentes posições que elas ocupam no espaço privado mãe, mulher e esposa -, e que têm a ver com o cuidado da vida, com o afeto, com o cotidiano, com as relações dialógicas, que ao longo da história foram desqualificadas para atividades intelectuais. Elas se consideram portadoras de outras experiências $e$, consequentemente, de novos valores para a teologia. Se, no processo de produção da teologia feminista, algumas teólogas se aproximam dos referenciais teóricos do feminismo da diferença $e$ do ecofeminismo, essa mesma postura pode ser percebida nas narrativas das entrevistadas. Elas parecem falar a partir desse lugar político teórico.

A afirmação de que elas fazem a diferença como sujeito feminino, dentro de um espaço masculino, por meio das experiências singulares que elas trazem para o universo teológico, não rompe com a estrutura androcêntrica, mas do ponto de vista das concepções de Rosi Braidotti (1999; 2004), das quais nos apropriamos, funciona como uma estratégia política que pretende

\footnotetext{
${ }^{19}$ Parte dessa reflexão tem como base uma entrevista concedida à revista IHU On-Line intitulada "Mulheres: sujeitos femininos de saber teológico" (Furlin, 2014b).
} 
dar visibilidade e legitimidade às mulheres, na posição de sujeitos do ensino. Trata-se de um sujeito feminino, que não é desqualificado e nem irrepresentável.

Aparentemente, a positivação do feminino ocorre dentro dessa contradição, ou seja, ao mesmo tempo em que as docentes assumem isso como uma posição política também acabam reforçando os atributos que essencializam um feminino produzido pelo sistema simbólico masculino. Segundo os argumentos de Lauretis (1994), é dentro desse paradoxo que se encontra a possibilidade da existência do sujeito feminino feminista. De acordo com Costa (2002:66),

esse movimento para dentro e para fora das representações/discurso não gera uma negatividade, mas ao contrário, uma positividade que também fala dos investimentos particulares do sujeito, sejam materiais, emocionais ou intelectuais.

Lembramos que Irigaray (2010) considera ser possível uma ética da diferença sexual que não deriva de uma diferença sexual essencializadora, mas da questão que é colocada por essa diferença. Essa ética, em primeiro lugar, seria uma forma crítica ao status quo e à transformação das estruturas construídas sob a ideia de um sujeito único, da ordem discursivo-normativa masculina (Beltran, 2010), que é tão evidente dentro das estruturas teológicas. Para Irigaray, a ética como uma positivação do feminino tem o sentido de respeito, de fazer justiça, de deixar ao outro a sua liberdade e o seu sexo. Nesse caso, de deixar as mulheres serem aquilo que elas não puderam ser, porque haviam sido condenadas ao silêncio e à não participação na ordem religiosa, política $e$ ética, justamente porque se considerava que elas tinham um "corpo inferior", cuja função primeira era a maternidade. E, agora, nesse lugar acadêmico, as docentes estão justamente reivindicando o direito do seu sexo, o direito ser sujeito feminino, com igual capacidade de saber e de poder enunciativo. 
Muitas vezes, as experiências que as docentes vivenciam, em diferentes circunstâncias da vida, são apresentadas como se fossem de uma singularidade universal, colocadas pela diferença sexual, como podemos verificar na narrativa de Priscila, que segue abaixo. Entretanto, consideramos que essas experiências resultam das condições socioculturais que foram colocadas para as mulheres. Ou seja, são experiências que se produziram por meio de um processo interativo do eu com a realidade social, que acabam produzindo uma série de significados e valores $e$ que passam a ser compreendidos como uma experiência de sujeitos específicos (Lauretis, 1994). Essa subjetividade produzida por processos de incorporação de significados e de experiências acabam orientando a percepção de mundo $e$ as ações dos sujeitos. Então, essa diferença de percepção "de viver e de sentir a vida, de ter um olhar diferenciado na produção da teologia" resulta de uma construção sociocultural que produziu subjetividades femininas e masculinas e não de uma singularidade a priori feminina ou masculina, dada pela diferença de sexo, como parece insinuar alguns aspectos da narrativa de Priscila.
[...] Quer dizer, tem muito a ver com a experiência que a gente tem de vida. Assim, acho que faz muita diferença, porque o homem e a mulher são muito diferentes [...]. As mulheres devem ser iguais na dignidade, mas são muito diferentes no modo de ver a vida, de viver, de sentir, experimentar. O olhar feminino de quem faz teologia é diferente. As mulheres ensinam de outro modo. É muito diferente. Eu acho que as mulheres fazem a diferença $e$, a gente tem essa fala dos alunos (Priscila, 60 anos).

Essa narrativa ilustra substratos também presentes nas estruturas de outras narrativas sobre o sentido de "marcar a diferença" no universo teológico, vindos do olhar e de uma subjetividade feminina, que faz com que se levantem aspectos não pensados pelos homens, tanto na organização das disciplinas como na produção do saber. Pode-se afirmar que no contexto da estrutura acadêmica da teologia, normatizada pelo masculino, a 
ênfase na "diferença feminina", ainda que, contraditoriamente, expressada no singular, pode ser entendida como uma estratégia usada para legitimar a ação e a presença de um coletivo ${ }^{20}$ de mulheres, que ficaram, por muito tempo, ausentes desse lugar acadêmico, com "poderosa" estrutura, por serem instituídas dentro dos pressupostos de uma cultura patriarcal hierárquica, que privilegia a visão masculina de mundo. Nesse sentido, segundo Spivak (1989, apud Costa, 2002), dependendo do contexto social, sobretudo se esse for marcado por uma poderosa estrutura masculina,

o essencialismo positivo ou estratégico é uma posição que as feministas devem arriscar, embora "conscientes quanto aos limites do (auto)posicionamento - individual e coletivo" - de forma que este posicionamento possa ser estrategicamente efetivo (Costa, 2002:72) ${ }^{21}$ [para a vida $e$ ação das mulheres].

Considerando esse contexto, e o reforço da diferença, por parte das docentes entrevistadas, retomamos o pensamento de Braidotti (2004), a qual alerta para que a categoria diferença sexual não seja compreendida como uma categoria problemática e nem seja separada radicalmente da revisão de outras categorias, tais como: raça, etnia e outras diferenças sociais codificadas. Contudo, a autora enfatiza que se deve seguir privilegiando a

\footnotetext{
${ }^{20}$ Observa-se que essas docentes, em geral, não falam só de si, mas do sujeito "mulher" como um coletivo. Embora não estejam organizadas em um movimento coletivo, elas se conectam por estarem situadas em um mesmo contexto de ação, por compartilharem da mesma memória de discriminação sexista, por produzirem estratégias políticas de uma afirmação positiva do feminino e, sobretudo, por imaginar possibilidades de uma vida melhor para as mulheres, apesar dos limites institucionais.

${ }^{21}$ Para Spivak (1989), esse posicionamento "oferece uma percepção mais prática do pós-estruturalismo do que aquele tipo de metafísica negativa, sempre nervosa, com a possibilidade do essencialismo estar de tocaia pelos cantos" (apud Costa, 2002:73).
} 
identidade sexual, isto é, o fato de se ter um corpo de mulher ${ }^{22}$, como o primeiro lugar de resistência. Esse lugar se define como um processo de constituição múltipla, complexa e de facetas potencialmente contraditórias das posições de sujeito, como sugere Tereza de Lauretis (1994).

Outra questão assinalada pelas docentes, no processo do devir sujeitos femininos de saber, tem a ver com a construção contínua dos espaços de ação já conquistados, uma vez que eles não são ainda legitimados para elas. Desse modo, elas precisam constantemente negociar, reafirmar ou reconquistar o lugar que ocupam, por meio de resultados, por vezes, melhores que seus pares, sem o direito de "errar", porque isso acabaria fortalecendo os antigos discursos de gênero que as inferiorizaram. ${ }^{23} \mathrm{~A}$ todo o tempo, em suas narrativas, as docentes assumem uma postura reflexiva e crítica diante dos códigos normativos de gênero, o que revela que elas têm consciência dos dispositivos de poder que se inscrevem no interior das relações de gênero (Scott, 1990) e que impõem pesos e medidas diferentes para os distintos sujeitos do ensino.

Acredita-se que a atitude reflexiva, evidente nas narrativas das docentes, é estabelecida por meio de uma relação consciente com os códigos normativos de gênero. No sentido de Foucault (1999), isso não pode ser entendido como uma simples oposição ao poder, mas como uma capacidade de identificar os "jogos de verdade" inscritos nas práticas institucionais que limitam as

\footnotetext{
${ }^{22}$ Convém lembrar que, em Braidotti, o corpo não é só biológico, mas é um ponto de superposição entre o físico, o simbólico e o sociológico. Ela toma o simbólico no sentido pós-lacaniano, isto é, como referência à uma estrutura estratificada de significação da linguagem, em que a linguagem encapsula as estruturas fundamentais de uma determinada cultura (Braidotti, 2004:42).

${ }^{23}$ Essa necessidade de conquista constante, que exige das mulheres resultados melhores que dos homens para permanecer em alguma posição profissional, não é algo que ocorre especificamente nas instituições de ensino teológico, mas uma situação recorrente no mercado de trabalho, em diferentes espaços sociais que, historicamente, foram atribuídos ou considerados como lugares de ação do sujeito masculino.
} 
possibilidades de ação para as mulheres e o seu processo de devir sujeitos femininos de saber teológico. Por meio dessa consciência $e$, desde dentro dos "jogos de poderes", elas podem construir as suas possibilidades do vir a ser, a partir de uma ética de si, como se pode ler na seguinte narrativa.

Ser homem e ser mulher na área do saber teológico não é a mesma coisa, porque para o homem é como que se já fosse uma coisa certa, como se ele estivesse num lugar determinado e certo para ele, e a mulher está ali numa constante conquista de espaço, de aprovação. Nâo de aprovação, por aprovação, mais enfim, de mostrar que se é capaz, de mostrar que se pensa, que a razão não é território masculino, enfim né, dessa troca. Essa é a diferença né, de que a gente estar ali, nessa constante conquista de espaço $e$ de reafirmação desse espaço. É quase escatológico, 'já e ainda não' (risos), como aquelas coisas bem assim, sabe, é uma coisa bem escatológica porque já se tem o espaço mais ainda não. Sabe, é uma constante, dia a dia. Porque é no dia a dia que você tem que mostrar que é capaz, que é competente, que tem que garantir confiança, essas coisas assim, na relação com os homens $e$ com as mulheres também (Lidia, 39 anos, grifo da autora).

No desejo do devir sujeito mulher no universo teológico, o conteúdo da narrativa de Lidia deixa a entender que as docentes interagem com as dinâmicas institucionais e, de forma ambígua, se fazem cúmplices da mesma ordem instituída que lhes impõe um peso maior no processo de tornarem-se professoras de teologia. Essa cumplicidade, mais do que uma postura de submissão à ordem simbólica masculina, é uma posição de resistência política, em que muitas vezes um indivíduo necessita se adequar a certas convenções sociais, como estratégia de subjetivação ética. Nesse sentido, pode-se pensar que esse esforço de construção contínua de espaços, a que elas se submetem, esteja sustentado pelo desejo consciente de ser um sujeito feminino pensante e, portanto, não se trata de uma submissão passiva, mas ativa. Essa posição aparece 
expressa na frase de Lidia (39 anos): "Não é buscar aprovação por aprovação, mas enfim, de mostrar que se é capaz, de mostrar que se pensa e, que a razão não é território masculino, [...]". Observase expressamente a existência do desejo de marcar o lugar do saber teológico por uma afirmação positiva da alteridade.

Essa estratégia política de afirmação de si aparece como uma constante e se realiza por meio de práticas e experiências cotidianas, como Lídia (39 anos) acena: "porque é no dia a dia que você tem que mostrar que é capaz, que é competente; que tem que garantir confiança, na relação...”. De certa forma, essa é uma posição política porque, sutilmente, vai questionando a legitimidade do sujeito masculino como o único detentor de razão e de saber teológico e produz nas mulheres uma ética de si, no processo do vir a ser sujeito feminino. Isto é, na relativa submissão à norma social masculina, que as produziu seres desqualificados para o pensamento, elas desconstroem um imaginário fixo sobre o feminino, por meio de uma contramemória e afirmação de si, que ocorrem concretamente pelas suas experiências incorporadas em situações concretas, no sentido do argumento de Braidotti (2004). Assim, nessas experiências, e no sentido que elas dão para as suas práticas, podemos dizer que ocorre a genealogia do sujeito mulher no aqui e no agora da história, para além da linguagem dos homens, como afirma Lauretis (2000). Mas, também, como algo que permanece sempre como um projeto utópico de um devir, que se traduz nessa expressão: "uma coisa bem escatológica porque já se tem o espaço mais ainda não" (Lidia, 39 anos). Isto é, um processo de ressignificação que já começou e, no entanto, está sempre se produzindo (Braidotti, 2004), tanto em relação à própria subjetividade como na construção de espaços de agenciamento.

Vale reforçar, ainda, um outro aspecto que aparece como significativo nas narrativas das docentes e que é valorizado por elas, no processo do devir sujeito feminino de saber teológico. Trata-se das práticas acadêmicas que elas realizam em um espaço historicamente masculino, tais como: aulas ministradas em disciplinas eixos da grade curricular do curso de graduação em teologia, que até então eram de domínio dos sujeitos masculinos e 
celibatários; a produção acadêmica pautada na perspectiva de gênero; os lugares de poder e de liderança que ocupam; as inúmeras publicações e orientações de trabalhos acadêmicos que realizam, por vezes em maior quantidade que as dos sujeitos masculinos; as iniciativas que inauguram $e$ os significados produzidos nessas ações. Essas práticas acadêmicas são experiências situadas e funcionam como estratégias políticas que desnaturalizam a ideia de uma identidade feminina em que o simples fato de ser mulher já era um elemento desqualificador para atividades do pensamento. Reforçam, ainda, uma ética de si e a afirmação positiva do feminino, de um sujeito que é capaz de pensar, ensinar e produzir saber.

Tais práticas mostram como elas tecem seus lugares $e$ possibilidades de ação por meio de um processo que envolve estratégias de poder, afirmação positiva de si, autoconsciência, reflexividade e desejo de equidade e igualdade, num lugar em que a lógica de gênero é masculina. São práticas situadas e que parecem funcionar como contramemórias, no sentido de desconstruir a imagem desqualificada de "mulher" do sistema simbólico masculino, para produzir uma imagem positiva $e$ legítima, como sujeito de saber. Dito em outras palavras, produz um deslocamento subjetivo de um feminino pejorativo e inferior, para um feminino positivo, dotado de capacidade intelectual.

Partindo da concepção butleriana, poder-se-ia considerar que a reivindicação pelo reconhecimento identitário ou de uma autoafirmação positiva do feminino e de uma justa redistribuição de poder, como expressão do desejo do devir sujeito feminino de saber teológico, é o que gera a consciência reflexiva sobre os limites normativos institucionais e, consequentemente, potencializa a criação de estratégias políticas de ação/agência. Isto é, os limites historicamente impostos às mulheres, na área do ensino e da produção do saber teológico, também geram as condições de potência, como capacidade de ação, de produção de novos efeitos no interior de uma instituição androcêntrica. De forma que esses novos efeitos se vinculam com o que se define como práticas transgressoras ou "inovadoras" (Butler, 2009b). É o poder que se 
desloca e se torna potência, capacidade de ação das mulheres. Elas, agora, fazem a experiência de ser um sujeito racional capaz de ensinar, produzir e "distribuir" conhecimento teológico.

O processo de "tornar-se" ou "do vir a ser" embora vinculado pela memória do passado, de um simbólico negativo, é sempre uma história genealógica que não repete o passado, mas se ativa no presente no sentido de contramemória, ou seja, é "uma história sempre do tornar-se, aqui e agora, enraizada na prática, na contradição, na heterogeneidade" (Lauretis, 2000a:27, tradução da autora). Porém é um devir contínuo que se conecta coletivamente pelo mesmo desejo imaginado e utópico de um processo de potencialização e de ressignificação que já se iniciou, mas que ainda não tem um produto final (Braidotti, 2004). E, isso parece brindar para as docentes a esperança da possibilidade e as energias para continuarem lutando, no presente, pelo seu devir sujeito mulher e marcar o universo do saber teológico por uma alteridade positiva e pela inserção de novos valores, apesar dos limites que elas ainda encontram nesse lugar de saber.

Tal postura, seguindo as concepções teóricas de Braidotti, nos possibilita dizer que essas docentes podem ser pensadas na perspectiva do nomadismo ${ }^{24}$, porque elas constantemente buscam desconstruir a identidade fixa de um feminino pejorativo por meio de práticas situadas, afirmando-se positivamente como sujeito "mulher". As suas ações e os seus posicionamentos críticos diante da estrutura simbólica masculina, que continua sendo reproduzida nas relações $e$ nas práticas institucionais, podem ser compreendidas como atos de liberdade, de reflexividade e de resistência política aos dispositivos de poder que têm discriminado e inferiorizado o feminino. Trata-se de uma postura crítica de um

\footnotetext{
${ }^{24}$ Segundo autora, o estilo nômade tem a ver com transições e passagens, sem destinos predeterminado ou "terras natais perdidas" $e$, por isso, se refere, também, ao tipo de consciência crítica que resiste a se ajustar aos modos de pensamento e comportamento codificados. É a subversão ao conjunto de convenções que define o estado nômade, não o ato literal de viajar (Braidotti, 2004).
} 
sujeito coletivo - Mulher ${ }^{25}$ - que resiste a se ajustar ao modelo de uma feminilidade desqualificada, colocando-se sempre no processo do "tornar-se", que tem a ver com uma transição nunca concluída. Talvez essa consciência nômade e a imaginação utópica de um devir sujeito "mulher" e de marcar um lugar de ausência histórica por uma alteridade positiva, que tem algo a contribuir no universo do saber teológico, possam explicar a razão de essas docentes continuarem atuando na marginalidade de um lugar de saber em que poucas mudanças estruturais parecem ser possiveis.

\section{Considerações finais}

Este trabalho permitiu evidenciar que o ato de cruzar fronteiras de gênero em campos profissionais "masculinos", como é o campo do saber teológico, é permeado de desafios, de limites, de convenções normativas de gênero que precisam ser superadas, de modo que o constituir-se sujeito feminino da docência na teologia, não é algo passivo, mas uma questão tensa, porque se produz na relação com a norma hegemônica (masculina $e$ celibatária), que sempre foi legítima no universo do saber teológico.

Indubitavelmente, o universo acadêmico da teologia católica tem sido fortemente estruturado por discursos, representações de gênero e práticas institucionais, de uma ordem simbólica androcêntrica; dinâmica que, ao longo da história, produziu a legitimidade do sujeito masculino nos espaços de liderança $e$ de produção do saber $e$ a inferioridade $e$ a desqualificação das mulheres, privando-as do seu protagonismo, como sujeitos femininos de saber. O gênero, nesse sentido, vai além das atribuições de masculinidade e feminilidade. Ele também se

\footnotetext{
${ }^{25}$ Aqui tomamos o termo "Mulher" segundo a construção de Braidotti (2004), ou seja, como categoria política no sentido coletivo e agregador dos múltiplos marcadores sociais de identidade. Como posição política do sujeito e não na perspectiva essencialista, mas como resultado de uma experiência situada $e$ histórica.
} 
codificou nas práticas institucionais, nas subjetividades e nos discursos teológicos, ou seja, ele aparece como um princípio estruturador de práticas, crenças, valores e saberes. De modo que as representações simbólicas do discurso teológico tradicional funcionaram como uma tecnologia social de gênero que produziu implicações concretas, tanto sociais quanto subjetivas na vida das mulheres. Isso, em parte, explica a presença reduzida da docência feminina na teologia, cuja inserção é também resultado dos processos de transformação sociocultural do mundo contemporâneo.

Em termos numéricos, a graduação em teologia apresenta altos índices de assimetria entre a participação da docência masculina e a feminina. Esses índices, de certa forma, estão vinculados às dinâmicas de poder de uma instituição, cujas estruturas continuam impregnadas de práticas sexistas e de um sistema simbólico de gênero que ainda produz barreiras para a subjetividade das mulheres $e$ para a sua ação no ensino $e$ na produção do conhecimento. Por outro lado, a presença de mulheres na docência, ainda que reduzida, vem desafiando os códigos convencionais $e$ as fronteiras de gênero de um lugar profissional majoritariamente masculino. Trata-se de uma presença que é, ao mesmo, tempo simbólica e política, porque subverte uma convenção social estabelecida, de um lugar estruturado, historicamente, como não inteligível para as mulheres. Essa presença transgressora, sem dúvida se deve a um agenciamento ético e político de mulheres, que também se afirmam sujeitos dotados de capacidade intelectual.

Nesse universo de saber, as mulheres buscam afastar-se do modelo de subjetividade do sistema simbólico da moral católica tradicional, por meio de suas práticas e de um processo constante de desconstrução e desnaturalização dos significados da cultura patriarcal, que elas mesmas haviam assimilado. Pode-se afirmar que, desse modo, elas produzem deslocamentos subjetivos, ou uma produção ética de si que se constitui pela experiência vivida, em contextos situados da história presente. Porém, é um processo 
nunca concluído, porque a luta contra os efeitos do poder é contínua.

Dentro de uma estrutura hierárquica e masculina, as docentes aparecem como sujeitos de enunciação e de produção de novos significados. Isso porque, ao se aproximarem ou, explicitamente, assumirem o feminismo da diferença, como uma posição política, elas rejeitam a lógica da identidade feminina negativa, do sistema simbólico masculino que subsumiu as mulheres. Porém, de forma alguma elas parecem rejeitar a igualdade, porque defendem igualdade na distribuição de poder $e$ nas condições de reconhecimento profissional. Nesse caso, nota-se uma espécie de hibridez que faz a "diferença na igualdade e a igualdade na diferença". De certa maneira, este estudo apontou que nem sempre a diferença sexual tende a desvalorizar as lutas políticas, uma vez que, em contextos fortemente marcados por uma estrutura poderosa, hierárquica e masculina, como o são as instituições católicas, ela continua sendo uma postura política estratégica, como enfatizamos no decorrer deste artigo.

No caso da teologia, a postura assumida pelas docentes entrevistadas em favor da diferença aparece como uma luta, no sentido de esvaziar a feminilidade de um conteúdo essencialista $e$ negativo. Contudo, não há um rompimento com a noção binária de gênero. Outras vezes, para além de uma postura de sujeito "mulher" universal, em contraposição a um sujeito masculino também universal, as narrativas apontam que elas se constituem por diferentes experiências situadas e contextuais, que fazem da "mulher" um sujeito múltiplo. Isto é, um sujeito atravessado por distintas experiências, que emergem de diferentes posições de sujeitos que elas assumem, no cotidiano de suas vidas (mãe, esposa, professora, religiosa, teóloga). Essa concepção se aproxima das posições das feministas contemporâneas pósestruturalistas como, por exemplo, de Braidotti (2004), para qual a diferença sexual inclui todas as diferenças. Assim, para além das críticas que são feitas às correntes do feminismo da diferença 
sexual de Irigaray e de Braidotti ${ }^{26}$ e, apesar de suas possíveis contradições teóricas, essas posições assumidas, como estratégias políticas, ainda parecem ser necessárias para compreender a ação dos sujeitos em determinados contextos sociais, como é o caso das instituições católicas de teologia.

As práticas acadêmicas que as docentes realizam, embora produzam um efeito de contramemória à um modelo de feminino desqualificado da ordem simbólica masculina, também têm mostrado a intensidade do trabalho acadêmico que as docentes assumem. Elas afirmam "fazer tudo mais e melhor que seus pares", inauguram novas práticas acadêmicas e "produzem de modo diferente", que nomeiam teologia feminista. Apesar das contradições que isso acarreta, ou seja, da cumplicidade com as convenções de gênero que exigem um duplo trabalho para a sua legitimação enquanto sujeito nesse campo de saber, ao mesmo tempo se constitui em um propósito político, que é o de representar-se por si mesmo, como "mulher", marcando esse lugar por uma identidade feminina que é positiva, mais do que propor mudanças estruturais. Isto é, elas parecem querer marcar o universo de saber teológico como um lugar da produção de si (individual e coletiva), de um sujeito feminino que tem direito a esse lugar social por uma trajetória - em parte pela formação profissional que possuem e, em parte, por uma ausência histórica , de modo que a sua presença se torne visível e reafirme os valores que vêm do universo feminino.

Nessa perspectiva, considerando uma história de discriminação sexista e de ausência nos lugares da produção e do ensino da teologia, bem como os desafios que essas mulheres enfrentam no momento presente, pode-se dizer que as práticas de agenciamento que elas produzem, por menor que sejam, tornamse importantes, porque estabelecem certa autonomia em relação a uma estrutura hierárquica e masculina. Isso nos leva a pensar que o "revolucionário" não se encontra só nos grandes processos de transformação social que se concretizam no tempo e no espaço,

${ }^{26}$ Dentre essas críticas encontramos as de Felski (1999), Butler (2003). 
mas também na produção de novos significados ou nas pequenas mudanças que ocorrem nas microrrelações sociais, que são tecidas no cotidiano da vida, como um modo novo de viver, de se produzir e de se reconhecer sujeito.

Usamos a categoria sujeito feminino de saber, como uma posição política de afirmação positiva da diferença sexual, que engloba vários conceitos. Assim, compreendemos que se trata de um sujeito múltiplo, porque as subjetividades dessas docentes estão atravessadas por diferentes experiências, que também as diferenciam umas das outras. É, ainda, um sujeito ético, na medida em que elas resistem ao sistema simbólico masculino de gênero, propondo um simbólico alternativo, por meio de práticas acadêmicas contextualizadas. É um sujeito nômade, porque os deslocamentos subjetivos já começaram no "aqui e agora" da história presente, mas é ainda um processo de devir não concluído, que envolve um constante empreendimento de energias, que se sustenta por um imaginário utópico de ser sujeito "Mulher". É um sujeito contraditório, porque se constitui dentro da ideologia masculina de gênero, pela apropriação do simbólico, mas, ao mesmo tempo, fora, porque elas imprimem significados novos, não imaginados no sistema hegemônico. É um sujeito individual que se remete ao coletivo, um "si mesmo para todas as mulheres", que se articula por afinidades ou pontos nodais que, nesse caso, trata-se da consciência de uma história comum de desqualificação do feminino e de discriminação sexista; de ausência histórica nos processos de produção do saber, em um espaço em que o normativo é o masculino; de uma espiritualidade compartilhada no sentido de sentirem-se vocacionadas para uma missão na teologia, do desejo de marcar o universo da teologia por uma alteridade positiva e de um imaginário utópico do devir sujeito feminino de saber teológico com reconhecimento acadêmico, que mobiliza ações no presente na esperança de um futuro melhor.

$\mathrm{E}$, para concluir, gostaria de acenar que essa luta situada $e$ contextual das mulheres docentes, no processo de se constituírem sujeitos femininos de saber teológico, evidentemente, embora 
específica e distinta, pode se reportar também a outros tantos campos que foram considerados, ao longo da história, masculinos, uma vez que, apesar das grandes mudanças socioculturais, ainda convivemos em um sistema com fortes resquícios da cultura patriarcal, a qual parece continuar necessitando da desigualdade, da hierarquia e da violência simbólica para subsistir. Um sistema que produz mecanismos de poder e de gênero, que parece se perpetuar também para dentro das instituições teológicas. Talvez, a luta dessas mulheres pelo agenciamento ético de si, no sentido de uma afirmação positiva da subjetividade feminina, pelo reconhecimento profissional e pela produção de novas simbologias e significados, como uma maneira de modificar o imaginário coletivo, nos faça acreditar que

\begin{abstract}
a transformação do mundo começa com a transformação de nossas mentes e a renovação de nossas mentes começa com a transformação das imagens que introduzimos nela, isto é, as imagens que penduramos em nossas paredes e as que levamos em nosso coração (Ward L. Kaiser). ${ }^{27}$
\end{abstract}

Oxalá, que a mudança de mentalidade também produza um processo de transformação nas estruturas hierárquicas e injustas, que ainda geram discriminação social de gênero, raça, classe, cultura..., em diferentes esferas da vida social.

\title{
Referências bibliográficas
}

AdELMAN. Miriam. $A$ voz e a escuta: encontros e desencontros entre a teoria feminista e a sociologia contemporânea. São Paulo, Editora Blucher Ltda, 2009.

\footnotetext{
${ }^{27}$ Esse pensamento tem me acompanhado nos sonhos de mudanças sociais, contudo no momento em que busquei citá-lo neste texto, não consegui encontrar mais a sua referência. Contudo, mesmo assim o citei porque ele dá ênfase à ideia desenvolvida na conclusão.
} 
AQUINO, Tomás. Questão 92 - Da produção das mulheres. In:

Suma Teológica. 2 ed. Porto Alegre, Escola Superior de Teologia São Lourenço de Brindes, 1980, artigo I. (Coleção v.2 )

ARCHER, Margaret S. Reflexividade e tratamento em "primeira pessoa" em Sociologia [< http://www.sbs2009.sbsociologia.com.br/ > - acesso em: 16 ago. 2009].

Beltran, Fina Birulés; Peiró, Àngela L. Fuster. Prólogo. In: IRIGARAY. Luce. Ética de la diferencia sexual. Vilaboa Espanha, Ellago Ensayo, 2010, pp.13-28.

BRAIDOTTI, Rosi. Diferencia sexual, incardinamiento y devenir. MORA Revista del Instituto interdisciplinario de Estudios de Género (5), Buenos Aires, Facultad de Filosofía y Letras, 1999, pp.08-19.

. Feminismo, diferencia sexual y subjetividad nómade. Barcelona, España, Editorial Gedisa, 2004.

BRUSCHINI, Cristina; LOMBARDI, Maria Rosa. Instruídas e trabalhadeiras: trabalho feminino no final do século XX. cadernos pagu (17/18), Campinas, Núcleo de Estudos de Gênero-Pagu/Unicamp, 2001, pp.157-196.

BUTLER. Judith. Problemas de gênero: feminismo e subversão da identidade. Rio de Janeiro, Civilização Brasileira, 2003.

- Dar cuenta de si mesmo: Violencia ética y responsabilidad. Buenos Aires, Mutaciones, 2009a.

- Cambio del sujeto: La política de la resignificación radical de Judith Butler. In: CASALE, Roland; CHIACHIO, Cecília (Orgs). Máscaras del deseo: una lectura del deseo en Judith Butler. Buenos Aires, Catálogos, 2009b, pp.65-111.

. Mecanismos psíquicos del poder: Teorías sobre la sujeción. 2 ed. Madrid, Ediciones Cátedra, 2010.

CHASsOt, Atico. A ciência é masculina? 4 ed. São Leopoldo, Editora Unisinos, 2009. 
Costa, Claudia Lima. O sujeito do Feminismo: revisitando os debates. cadernos pagu (19), Campinas, Núcleo de Estudos de GêneroPagu/Unicamp, 2002, pp.59-90.

DALY, Mary. The Church and the second sex. Londres, Harper Books, 1985.

FELSKI, Rita. The gender of modernity. Londres, Harvard University Press Cambridge, 1995.

. La doxa de la diferencia. MORA - Revista del Instituto interdisciplinario de Estudios de Género (5), Facultad de Filosofía y Letras, Buenos Aires, 1999, pp. 33-52.

FIORENZA, Elisabeth Schüssler. Discipulado de iguais: uma ekkesia-logia feminista crítica da libertação. Petrópolis, Editora Vozes, 1995.

Foucault, Michel. Microfísica do Poder. 14. ed. Rio de Janeiro, Edições Graal, 1999.

. A hermenêutica do sujeito. São Paulo, Martins Fontes, 2004.

. História da sexualidade: o cuidado de si. 9 ed. São Paulo, Edições Graal, 2007.

FuRLIN, Neiva. Teologia e gênero: a docência feminina em instituições católicas. Revista Eclesiástica Brasileira 284, Petrópolis, 2011a, pp.880-910.

- Teologia feminista: uma voz que emerge nas margens do discurso teológico hegemônico. Revista de Estudos da Religião, ano 11, n. 01, São Paulo, 2011b, pp.139-164.

. Relações de gênero, subjetividades e docência feminina: um estudo a partir do universo do ensino superior em teologia católica. Tese (Doutorado em Sociologia), UFPR, Curitiba, 2014a.

. Mulheres: sujeitos femininos de saber teológico. IHU On-Line, v. 447, UNISINOS, 2014b, pp.47-56.

- O gênero da modernidade e o gênero da teologia: impactos socioculturais do pensamento masculino. Revista Punto Género, n.4, Santiago - Chile, 2014c, pp.55-82. 
- Práticas discursivas, desigualdade de gênero e estratégias de resistência política na experiência de teólogas docentes. Teoria $e$ Cultura (10), n.1, UFJF, 2015, pp.87-101.

GRAF, Norma Blazquez. Epistemología Feminista: temas centrales. In: ; PALACIOS, Fátima Flores; EVERALDO, Maribel Ríos (coord.). Investigación feminista: epistemología, metodología y representaciones sociales. Cidade do México, DF, UNAM/CEIICH, 2010, pp.21-38.

HaRding, Sandra. Ciencia y feminismo. Madrid, Ediciones Morata, 1996.

IRIGARAY Luce. Ética de la diferencia sexual. Vilaboa Espanha, Ellago Ensayo, 2010.

LAURETIS, Teresa de. A tecnologia de gênero. In: HOLANDA, Eloísa Buarque de (org.). Tendências e impasses: o feminismo como crítica da cultura. Rio de Janeiro, Rocco, 1994, pp.206-242.

Genealogías feministas: un itinerario personal. In:

Diferencias: Etapas de un camino a través del feminismo. Madrid, horas y Horas La Editorial, 2000, pp.7-31.

LLANOS, Gabriela Castellano. Decidimos, hacemos, somos: discurso identidades de género y sexualidades. Cali, Colombia, Universidad del Vale, 2010.

Louro, Guacira L. Gênero, Sexualidade e educação. 3.ed. Petrópolis, Editora Vozes, 1999.

MinAYO, Maria Cecília de Souza de. Hermenêutica - Dialética como caminho do pensamento social. In: MINAYO, Maria Cecília de Souza de; Deslandes, Suely Ferreira (org). Caminhos do pensamento epistemologia e método. Rio de Janeiro, Editora FIOCRUZ, 2003, pp.83-107.

MINISTÉRIO DA EDUCAÇÃO. Indicadores sobre a educação superior no país. SINAES/INEP [<http://sinaes.inep.gov.br/sinaes/> - acesso em: 10 out. 2008].

OliveIRA, Elizabete C. P. de. Teologia feminista e poder. In: Encontro de Padres Casados do Brasil, 5., 2006, Salvador, 2006. pp.1-8 [ $<$ http://www.oraetlabora.com.br/mpc/teologia feminista_e poder.ht m\# ftnref9> - acesso em: 10 jun.2013]. 
RAGO, Magareth. Descobrindo historicamente o Gênero. cadernos pagu (11), Campinas, Núcleo de Estudos de Gênero-Pagu/Unicamp, 1998, pp.89-98.

RUETHER, Rosemary R. Sexism and God talk. Londres, SCM, 1983.

SCHIENBINGER, Londa. O Feminismo mudou a ciência? Bauru, EDUSC, 2001.

ScotT, Joan. Gênero: uma categoria útil de análise histórica. Revista Educação e Realidade (16) n.2, Porto Alegre, UFRGS, 1990, pp.522.

SPIVAK, Gayatri C. Interview with Angela McRobbie. Block (10), 1985, pp.5-9.

TEPEDINO, Ana Maria. A mulher: aquela que começa a "desconhecer o seu lugar". Perspectiva Teológica (43), Belo Horizonte, ano XVII, 1985, pp.375-379. 